\title{
La relevancia de la vivienda social en el origen de la arquitectura contemporánea
}

\author{
Jesús López Díaz \\ Profesor Historia del Arte. UNED
}

\begin{abstract}
RESUMEN
Este artículo intenta poner de manifiesto el relevante papel que jugó la vivienda social en el origen de la arquitectura contemporánea de vanguardia durante los años de gestación de este movimiento en el paso del siglo XIX al $X X$, dentro del marco social y económico que configuró la segunda revolución industrial. El proceso descrito arranca en Inglaterra con el surgimiento de las utopias de Owen y Fourier, que desembocaron en el auge de las construcciones de ciudades y viviendas obreras promovidas no sólo por utópicos, sino también por industriales cercanos al socialismo y filántropos, $y$ hacia finales del siglo xix por los denominados higienistas. Las escasas realizaciones llevadas a cabo naufragaron

la mayoría de las veces, pero su espíritu jdealista supuso el cultivo del antiindustrial, conservador y socialista movimiento inglés del Arts \& Crafts.

Arts \& Crafts devino en un movimiento proartesano muy cercano a los planteamientos de la ciudad jardín formulados a finales de siglo por Ebenezer Howard. Sin embargo, sólo el salto a Alemania a través de Muthesius y el movimiento de la Deutsche Werkbund
\end{abstract}

\begin{abstract}
This paper tries to show the relevant role played by social housing in the origin of the contemporary architecture during the first years of beginning of this movement in the xxth century, inside the social and economic frame that formed the second industrial revolution.

The described process starts in England with the emergence of Owen's and Fourier's utopias, which ended with the summit of the constructions of cities and. working housings promoted not only by Utopians, but also by manufacturers near to the socialism and philanthropists, and towards the ends of the xixth century by the hygienists. The few actions performed led to the failure the most of the times, but their idealistic spirit supposed the culture of the anti-manufacturer, conservative and socialistic English movement of the Arts \& Crafts.

Arts \& Crafts became into a craftsman movement, close to the expositions of the garden-city formulated by $E$. Howard. Nevertheless, only the jump to Germany thnough Muthesius and the Deutsche Werkbund movement allowed to understand to the new contemporary architecture the importance of the industry
\end{abstract}


permitieron entender a la nueva arquitectura contemporánea la importancia de la industria y la máquina, desde una perspectiva marcada por el socialismo, como facilitadoras de una solución realista al problema de la vivienda social en serie a través del diseño racional, la estandarización y la prefabricación. De este modo la vivienda social de los años veinte

pasó a convertirse en el eje central del discurso de la arquitectura contemporánea, apenas cien años después del sueño utópico de Owen. and the machine from a perspective marked by the socialism, as providers of a realistic solution to the problem of the social housing through the rational design and the standardization. Thus the social housing of the twenties became the central reference of the contemporary architecture just a hundred years after Owen's Utopian dream.

\section{VIVIENDA SOCIAL Y CIUDAD CONTEMPORÁNEA}

En el pasado siglo $x x$ existieron dos momentos transcendentales en la relación entre vivienda social y arquitectura contemporánea: las experimentaciones del periodo de entreguerras (con los modelos erigidos en las grandes ciudades alemanas, en la Viena "roja» o en las nuevos barrios holandeses; y con las teorías recogidas en los primeros CIAM); y concluida la ll Guerra Mundial en la paradigmática Unité d'Habitation (Marsella, 1946-52), obra de Le Corbusier. En España el punto álgido - y casi pasajero- de esta relación entre la arquitectura con mayúsculas y la vivienda social, se produjo en el diseño de los Poblados Dirigidos y de Absorción construidos en la periferia madrileña a finales de los años $50^{1}$.

Estas cumbres tan conocidas, no son sólo el reflejo de una transformación en la arquitectura, sino que son respuesta a los profundos cambios socioeconómicos del siglo xx. No es por gusto que la arquitectura dejara de construir palacios y catedrales, sino que las transformaciones vividas en el pasado siglo rediseñaron radicalmente la relación entre arquitectura y sociedad. Ahora era la sociedad (o el Estado como supraestructura) quien se convertía en el principal mecenas de los arquitectos.

La nueva sociedad se asentaba en las ciudades transformándolas en megalópolis, y el gran reflejo del cambio visual de las ciudades se percibe en la expansión de la vivienda y de las vías de comunicación. Si comparamos los planos de nuestras urbes entre 1900 y 2000 todo el área añadido está mayoritariamente ocupado por viviendas. La vivienda -y por necesidad las vías de comunicación que unen residencia con el resto de las funciones del ser humano- es la gran transformadora del entorno urbano.

1 Fernández-Galiano, IsaSi y Lopera: La quimera moderna. Los Poblados Dirigidos de Madrid en la arquitectura de los 50, Madrid, H. Blume, 1989. 
Este cambio de escala ha llevado a la gran arquitectura a preocuparse también por la vivienda social, en un gesto en parte democratizador que ha permitido al gran público a acceder a una vivienda "firmada". Y aunque los "gestos" de esta gran arquitectura son hoy sólo eso, gestos aislados desconexos de teorías urbanas y sin ningún ánimo de guía, en aquellos dos momentos históricos señalados más arriba, la pretensión de la arquitectura contemporánea era casi utópica, intentando mostrar un camino al urbanismo y a la arquitectura presente y futura.

\section{LA VIVIENDA SOCIAL EN LA HISTORIA DE LA ARQUITECTURA: UTÓPICOS, FILÁNTROPOS E HIGIENISTAS}

Vitruvio, en el Libro Il de su gran obra, expone su teoría sobre los orígenes de la arquitectura. La búsqueda de protección frente a las fuerzas de la Naturaleza, la construcción de la vivienda, es el origen del desarrollo de la arquitectura. Más tarde, en su Libro VI, al tratar la vivienda privada, hace recomendaciones sobre aspectos orográficos, climáticos y astrales para una mejor ubicación de la construcción; mientras que para su diseño y compartimentación recomienda ajustar los espacios dependiendo de la categoría del dueño².

Quince siglos después es Leon Batista Alberti quien recupera el legado vitruviano de la tratadística arquitectónica, rememorando la comparación platónica entre casa y cuerpo. Para Alberti todo el arte de construir requiere de seis elementos: hogar, solar, distribución, muros, cubiertas y vanos; y en su texto también hace recomendaciones sobre la elección del lugar y las orientaciones dependiendo de los criterios climáticos.

La tratadística renacentista está llena de citas sobre las construcciones destinadas a vivienda, incluso para las amplias clases bajas urbanas y rurales. Un ejemplo muy interesante se nos muestra en la descripción que hace Filarete de las viviendas para obreros, a modo de pequeñas colonias de habitaciones -que no viviendas-adosadas sin más compartimento: "Para un pobre que no puede llegar a tanto aderezo, que se haga lo que se pueda, con tal de que esté a cubierto. Tal casa no necesita mayor medida ni distribución de sus miembros, sino únicamente un rectángulo (...) la distribución hazla a tu manera, porque éste tiene poco dinero y no precisa calentarse los cascos para gastar, sino para saber administrarlo, de modo que con poco tenga una casa. Haz lo que puedas". ${ }^{3}$

2 «De la forma de las casas, según la diversa categoria de las personas", en cap. VIII, Libro VI. VITRuvio, M. L.: Los diez libros de arquitectura. Barcelona, Iberia, 1997, págs. 152-154.

3 Pedraza, P.(ed.): Tratado de arquitectura. Antonio Averlino "Filarete", Vitoria, Ephialte, 1990, pág. 201. 
Quizás podríamos estar tentados de pensar que las palabras de Filarete tuvieron cierto eco en la arquitectura, y la vivienda social permaneció al margen de la historia arquitectónica. Sin embargo habrá que esperar algunos años $-y$ las transformaciones sociales paralelas - hasta que en el mundo del arte tengan reflejo las preocupaciones sociales. Ciertamente, las referencias a lo que podemos denominar ampliamente como vivienda social (o popular, en estos siglos) están presentes en los tratados sobre la ciudad ideal del mundo renacentista, y en cierta medida su presencia en el urbanismo utópico va a continuar con las obras de los arquitectos utópicos de la Revolución Industrial y el siglo XIX.

Poco a poco algunos arquitectos irán sumando sus voces a las críticas sociales al proceso industrializador. Un primer y notable ejemplo lo encontramos en la cuna de la Revolución Industrial, Inglaterra, cuando en 1781, John Wood hijo, publica su obra sobre los cottages, desde donde critica las condiciones de vida de las viviendas de los trabajadores rurales y urbanos, aportando en aquel trabajo algunos diseños posibles de viviendas «sociales».

Aunque quizás la primera y más famosa realización de viviendas sociales (tras algunos ejemplos aislados llevados a cabo por diferentes rincones de Europa) la encontramos en New Lanark (Glasgow, 1815), obra del industrial socialista Robert Owen (1771-1858). Todo el siglo xIX se irá nutriendo de pequeñas ciudades o barriadas erigidas por empresarios y arquitectos con preocupaciones sociales (aunque como Owen, para muchos de ellos la vivienda digna e higiénica debía ir acompañada de un salario justo, y de medidas sociales y educativas).

El catálogo de ejemplos cada vez menos aislados debería citar al paternalista proyecto de sir Titus Salt (Saltaire, Bradford, Yorksire, 1850), desarrollado a modo de ciudad fabril con edificaciones e instituciones tradicionales (iglesia, instituto, baños públicos,...). Sin embargo, desde un punto de vista teórico y moral, es la utópica visión de Charles Fourier, presentada en su escrito Le Nouveau Monde Industriel (1829), una de las soluciones más radicales del momento. Los malogrados falansterios diseñados por Fourier en Inglaterra y Estados Unidos, alojaban comunidades rurales apoyadas en la industria ligera de las manufacturas; aunque lo más destacable para la relación entre vivienda social y arquitectura, lo constituye el hecho de que su trazado se modelara a partir del esquema de Versalles. Como señala Kenneth Frampton, es Victor Considérant, el discípulo de Fourier, quien en 1838 mezclaba la metáfora de Versalles con la del barco de vapor, preguntándose «si era más fácil alojar a mil ochocientas personas justo en medio del océano que alojar en una construcción unitaria a mil ochocientas buenos campesinos." El historiador británico nos recuerda que "esta particular refundición de la comuna y el barco iba a ser retomada por Le Corbusier más de un siglo des- 
pués, en su comunidad autosuficiente o Unité d'Habitation, realizada con alusiones a Fourier $(. ..) .{ }^{4}$

Es lógico, dentro del contexto europeo, que en la industrial Inglaterra del siglo $X I X$ se sucedieran la mayoría de los intentos por crear unas viviendas dignas para la cada vez mayor población obrera. Desde un punto de vista crítico, Frampton afirma que «el esfuerzo de la industria por cuidar de sí misma adoptó muchas formas: desde las ciudades modelo ligadas a manufacturas, ferrocarriles o fábricas hasta proyectos de comunidades utópicas entendidas como prototipo de un supuesto estado ilustrado aún por llegar. ${ }^{5}$ Así podemos citar en este sentido los ejemplos promovidos por el Coronel Akroyd (Copley, 1837; Akroydon, 1885), o por Francis Crossley (West Hill Park, Halifax, 1863-68), ejemplo éste realizado por Joseph Paxton (el autor del Crystal Palace, una de las primeras grandes estructuras modernas de hierro y cristal destinada a alojar la Gran Exposición de Londres de 1851).

Al cruzar al continente encontramos uno de los más prematuros ejemplos de vivienda social, el conjunto urbano de Fuggeri promovido en 1516 por uno de los entonces hombres más ricos de Europa, Jakob Fugger. Pero es una solución aislada, y tenemos que esperar al siglo XIX para encontrar poco a poco más extendido el modelo de pequeñas ciudades obreras. Un ejemplo interesante se lleva a cabo en Mulhouse en 1853, donde un grupo de industriales construye unas viviendas para obreros que les son ofrecidas en propiedad, es el primer caso en este sentido, aunque el interés último de ios industriales era ejercer una «influencia moral» sobre los obreros al convertirlos en propietarios. ${ }^{6}$

Frente a este ejemplo de promoción de la propiedad privada se instala el modelo del industrial Jean-Baptiste Godin, quien en sus familisterios de Guise (18591877) promueve un hábitat colectivo deudor de los ideales de Fourier, a través de sus bloques residenciales en torno a un patio central iluminado cenitalmente.

Dentro de esta significativa corriente de empresarios empapados de los ideales socialistas, se encuentran también las realizaciones promovidas por el industrial Menier en Noissiel. Menier es uno de los primeros empresarios en producir hierro en el continente, y en sus villas obreras vuelca sus conocimientos sobre lo que se realiza en Inglaterra, además de consultar con Emille Müller (el arquitecto de Mulhouse). Aunque quizás el aspecto más destacado de su empresa radica en las consultas hechas a los futuros inquilinos de las viviendas, mayoritariamente unifamiliares.

${ }^{4}$ Frampton, Kenneth: Historia crítica de la arquitectura moderna, Barcelona, Gustavo Gili, 1998, pág. 22.

5 Ibídem, pág. 22.

${ }^{6}$ Siguiendo los ideales de Frédéric Le Play, y como señala Roger-Henri Guerrand, también, en cierto modo de Fourier. GuerRand, R.H.: «Au temps du paternalisme et de l'utopie», en Une Europe en construction. Deux siècles d'habitat social en Europe, Le Découverte, París, 1992, págs. 27-52. 
En definitiva, todas estas ciudades obreras se encuentran casi siempre más cercanas a las fábricas que a las ciudades ${ }^{7}$, resolviendo el alojamiento obrero de industrias concretas ( $\mathrm{y}$ los problemas de sus empresarios), y no el cada vez mayor hacinamiento de las ciudades, un problema que irá poco a poco situándose en el primer plano de las políticas de los países industrializados europeos, sin duda porque las consecuencias de este hacinamiento social revertían cada vez con mayor fuerza en la tensa vida política, social y económica.

Debemos nuevamente regresar a Inglaterra para encontrar los primeros informes de carácter institucional sobre los problemas generados por las malas condiciones de alojamiento de la clase obrera urbana (1770). Aunque será en 1842, con el informe Chadwick (llamado así por ser su creador Edwin Chadwick, quien desde 1833 había dirigido en Londres una comisión contra la pobreza), sobre las condiciones sanitarias de la población obrera, cuando se denuncie públicamente el estado de sus viviendas sin luz ni aireación, donde se acrecienta el riesgo de mortalidad por la falta de condiciones higiénicas, a la vez que, para la moral victoriana de la época, se favorece la «inmoralidad» sexual. Aparte de las medidas que se inician para mejorar estas condiciones en Liverpool en 1846, el interés del problema por parte del gobierno británico tiene su reflejo en la promulgación de la Public Health Act (1848, tras la creación en 1844 de una comisión real que estudiara la cuestión), por la que se dictan medidas que mejoran las condiciones higiénicas, fundamentalmente de las nuevas viviendas, además de ordenar la creación de un departamento de sanidad pública en cada municipio (encargado del alcantarillado, la distribución del agua, la recogida de basuras,...).

Un proceso similar tiene lugar en Francia, tras las devastadoras consecuencias producidas por la epidemia de cólera de 1832, que se cebó en la población mal alojada en las viviendas para obreros sin ninguna garantía sanitaria. Las voces de denuncia de los discípulos de Fourier se unieron al cada vez más nutrido grupo de los higienistas-moralistas (como el Dr. Villeme y su teoría sobre la «higiene social» de 1840), que ven una respuesta a sus quejas en la creación estatal de la «policía sanitaria», $y$ en las disposiciones urbanas del barón Haussmann, similares a las descritas en la Public Health Act inglesa. ${ }^{8}$

7 En este sentido, en España podríamos citar los ejemplos de las colonias obreras catalanas situadas entre ríos generadores de energía y sus fábricas adyacentes, lejos de los núcleos urbanos, como la Colonia Prat, 1828.

${ }^{8}$ Un texto similar al inglés es también publicado en forma de Ley por Francia en 1850. 


\section{EL NACIMIENTO DE LA VIVIENDA OBRERA}

Durante la segunda mitad del siglo XIX se producirán respuestas aisladas, aunque cada vez con mayor peso, al problema de la vivienda obrera. Son dos los grupos institucionales (aún no es el Estado el impulsor de las soluciones) quienes van a dirigir las principales acciones de respuesta al problema: los filántropos y los mencionados higienistas, y en muchos casos, sus iniciativas se desarrollarán íntimamente unidas. Su preocupación social nace de posiciones puramente morales y religiosas, en ningún caso comparables a las demandas igualitarias y sociales de los utópicos y empresarios socialistas como Owen, Fourier o Menier.

En el caso inglés, es el propio Chadwick quien inspira la Sociedad para la mejora de las condiciones de las clases trabajadoras, autora de la primera promoción de viviendas para obreros en Londres (1844). Henry Roberts ${ }^{9}$, el arquitecto autor del proyecto, diseñará posteriormente el prototipo de casa para obreros expuesto en la Gran Exposición de Londres de 1851; basado en un modelo repetitivo de vivienda con dos plantas y cuatro apartamentos en torno a una escalera común, un modelo de gran influencia en la vivienda obrera a lo largo del siglo. El hecho de que la vivienda obrera fuera expuesta en una gran Exposición no será un acontecimiento aislado, en las posteriores exposiciones universales al lado de los avances técnicos aparecerán también los avances en vivienda obrera, aunque habrá que esperar hasta finales de los años 20 para ver exposiciones «universales» de vivienda donde los avances técnicos (en los «laboratorios» que suponen las cocinas) se diseñen por y para las viviendas mínimas. ${ }^{10}$

El más prolífico de los filántropos británicos fue sin duda el banquero George Peabody, quien desde la década de 1860 hasta finales de siglo levantará un pequeño parque de unas cinco mil viviendas obreras en la ciudad de Londres. Su ejemplo fue seguido, con un más discreto número de construcciones, por Sydney Waterloo, William Austin o lord Rowton (con viviendas exclusivas para desempleados o recién llegados a Londres), y en Dublín por la Guinness Trust (1889).

En las grandes ciudades europeas del continente se produjo un proceso similar al londinense. Por un lado proliferaban las encuestas y tratados higienistas, como el Traité de la salubrité dans les grandes villes, obra de los doctores franceses Moufalcon y Polimiere (Lyon, 1846), editado el mismo año que el memorial sobre la situación en Bélgica redactado por el jurista católico Edouard Ducpétiaux, quien consiguiera promover en 1852 en Bruselas el primer Congreso de Higiene Pública.

${ }^{9}$ Roberts reflejará sus modelos y teorías en un texto que en su traducción francesa será prologado por Luis Napoleón Bonaparte, indicio de la exteorización institucional por el problema de la vivienda obrera.

${ }^{10}$ Como en la Weissenhofsiedlung de Stuttgart (1927). 
También en España se escuchan, tímidas, las voces de higienistas como el Dr. Felipe Monlau, quien denuncia en 1847 las míseras condiciones de la vivienda obrera catalana en su obra Elementos de higiene pública; o el madrileño Dr. León Luque, quien hace lo propio a través de su detallado estudio de topografía médica.

La respuesta política fue siempre la misma, una legislación que casi nunca surtiría efecto. En el caso español, siguiendo las ya mencionadas leyes inglesa y francesa, se dictaba en 1853 un Real Decreto que instaba a los gobernadores civiles de Madrid y Barcelona a la construcción de viviendas, que nunca se construirían, para gentes sin recursos. Sólo a finales de siglo aparecerán en nuestro país entidades caritativas como la Constructora Benéfica (Madrid, 1875).

No así en París ${ }^{11}$, donde a la cité Napoleon de la década de 1860 (donde hay un primer y avanzado intento de utilización del hormigón), le siguen la Societé philantropique (1888) el Groupe des Maisons Ouvrieres (1899) y la prolífica Foundation Rothschild. Es preciso destacar que para estas dos últimas entidades trabaja el arquitecto Auguste Labussiére, quien utiliza en algunas viviendas estructuras de hormigón.

Hacia finales de siglo, aunque en 1845 ya había sido denunciado vivamente por Engels cuando conoció las pésimas condiciones de vida de los obrero de Manchester ${ }^{12}$, el problema de la vivienda se había convertido en una cuestión política de primer orden, como parte, en muchos casos, de las reivindicaciones de los primeros parlamentarios de la izquierda europea. En el año 1885 se hizo pública la investigación llevada a cabo en Berlín sobre las condiciones higiénicas de la vivienda obrera, revelando la terrorífica situación en cuanto al número de personas que habitaban viviendas insalubres. Ese año, los socialistas ya estaban sentados en el Reichstag y Bismarck se vio obligado, para calmar la protesta social, a tomar las primeras medidas políticas para intentar resolver la situación.

Un año antes, una investigación similar llevada a cabo en el Reino Unido había servido para reforzar los poderes municipales con medidas ya más expeditivas como la posibilidad de expropiación por parte de los corporaciones locales ${ }^{13}$. Todo este proceso político desembocó en una nueva legislación con la aprobación de la Housing of Working Classes Act (1890), por la que los municipios intensifi-

1 FREDET, Jacques: Les Maisons de Paris ( 3 vols.). Éd de l'encyclopédie des nuissances, París, 2003, pág. 85.

12 BENÉvolo, L.: Orígenes del urbanismo moderno, Madrid, H. Blume Eds., 1979, págs. 41-51.

${ }_{13}$ Unos pocos años antes el industrial utópico inglés $W$. $H$. Lever, promotor de Port Sunlight cerca de Liverpool, ya habia propuesto la municipalización del suelo a través de la compra del mismo por parte de los ayuntamientos, para abaratar todo el proceso. Una medida que se demostraría exitosa al llevarla a efecto algunos ayuntamientos holandeses a partir de 1900, o las ciudades gobernadas por la socialdemocracia alemana en el periodo de entreguerras. 
caban sus acciones junto a las buildings societies, una especie de cooperativas creadas ya en 1836, pero hasta entonces con escasa actividad. Esta nueva legislación favorecerá la labor del recién creado London County Council (institución administradora del área metropolitana de Londres, 1888) quien con el socialista Sydney Webb y su mujer transformarán numerosos barrios y edificios, dentro de la inmensa labor que suponía mejorar el hábitat obrero en una urbe de más de seis millones de habitantes.

En Francia, en el año 1889, el católico antisocialista Jules Siegfried fundó la sociedad HBM (Habitations á bon marché), siendo el impulsor de la ley de 1894 que concedía ayudas fiscales y concedía financiación y ayudas para la construcción de estas viviendas para obreros (conocidas como $H B M$ ). Estos fondos llegaron desde la Casse des dépôts et consignations, una de las entidades financieras más importantes del mundo en este momento, aunque la construcción de este tipo de viviendas nunca alcanzó un número significativo.

El resto de los países europeos dictará normas legislativas cruzado ya el umbral de la nueva centuria. A finales del siglo xix y comienzos del xx son decenas los ejemplos de construcciones promovidas por entidades benéficas privadas, de viviendas erigidas por las propias industrias (es notorio el caso de las industrias del ferrocarril), acompañados casi siempre de tímidas intervenciones públicas.

En el caso español los últimos años del siglo xix contemplan una verdadera fiebre de estudios sobre higiene social, tratándose el tema incluso, en el primer Congreso Nacional de Arquitectos celebrado en Madrid en 1881, donde triunfa el criterio de Mariano Belmás contra los barrios obreros y a favor de la vivienda en propiedad con jardín ${ }^{14}$. El gobierno se hace eco de este debate y recoge en cierto modo las iniciativas europeas llevando a cabo investigaciones desde la administración para saber cuál era el estado de la vivienda obrera. Una primera encuesta se realiza en 1883 a cargo de la Comisión de Reformas Sociales promovida por el conde Segismundo Moret.

Sin embargo, tendrán que pasar casi treinta años para que las conclusiones de este informe o de los emitidos por una institución heredera de esta Comisión en 1907, el Instituto de Reformas Sociales creado en 1903, llevarán al gobierno español a emitir la primera legislación sobre la materia, la Ley de Casas Baratas de 1911.

14 El debate entre vivienda en propiedad y en alquiler, pero sobre todo entre vivienda unifamiliar y bloque colectivo, va a estar presente no sólo en España sino en toda Europa durante décadas y dividirá incluso a sectores de la izquierda. La resolución al problema a favor del bloque colectivo llegará en los años de la reconstrucción tras la ll Guerra Mundial. 


\section{LA MIRADA NOSTÁLGICA EN INGLATERRA: ARTS \& CRAFTS Y EL GARDEN MOVEMENET}

La mayoría de los ejemplos citados hasta ahora, aún siendo un nuevo camino para la arquitectura, no están dentro de la "gran arquitectura", aquélla que consideramos se convierte en la guía y el espejo del discurso historiográfico. Es, lógicamente, un proceso evolutivo que requería, como hemos comprobado, que el problema de la vivienda obrera se convirtiera en una de los temas más preocupantes para la sociedad y la política del siglo xix. No sólo por lo que se refería a las consideraciones higiénicas de estas viviendas, sino también por el problema urbanístico que conllevaba su ubicación dentro de una ciudad en pleno proceso industrializador.

Pero la arquitectura, para poder ofrecer soluciones reales, necesitaba sacudirse parte de este camino de utopía. Según Leonardo Benévolo, las utopías de Owen, Saint-Simon o Fourier, son ya criticadas en el Manifiesto del Partido Comunista de 1848, por identificar orden urbano con orden social y político. Así pues, 1848 se convierte, según Benévolo, en el comienzo del urbanismo moderno y el momento de separación entre la experiencia urbana y la izquierda política, el fin de la utopía y el triunfo de la técnica que en los años siguientes transformará Londres, París o Barcelona liderados por el nuevo conservadurismo europeo ${ }^{15}$.

Si las utopías de Owen y Fourier habían quedado desterradas, no ocurría lo mismo con los ideales socialistas en los que iban a beber buena parte de los grandes arquitectos de finales del XIX y las primeras décadas del siglo $\mathrm{XX}$, algunos de los cuales conseguirían articular poco a poco un discurso capaz de enfrentarse a la propuesta conservadora que transformaba las ciudades europeas en beneficio casi único de las clases burguesas.

De nuevo fue Inglaterra el punto de partida de este proceso evolutivo que partiendo de los ideales anti-industriales, recorrería dos caminos tan sólo en principio paralelos: el movimiento Arts \& Crafts y las primeras construcciones de ciudades-jardín siguiendo los principios enunciados por Ebenezer Howard. El origen de este discurso crítico hacia la ciudad industrial ya lo encontramos en el texto de Pugin de 1836, Contrasts, donde el arquitecto católico, anticlásico y defensor del neogótico, rememoraba con nostalgia su idealizada visión de la ciudad medieval, en medio de la deshumanizada ciudad actual donde malvivían fábricas y viviendas.

El legado de Pugin fue recogido por el crítico y ensayista John Ruskin, quien fundía su devoción al neogótico con su pasión por los ideales mostrados en los cuadros de los

${ }^{15}$ BenÉvolo, L.: Op. cit., págs. 61 y ss. 
pintores prerrafaelitas. Ruskin proclamaba la íntima unión entre arquitectura, religión y sociedad, $y$, fruto de sus fuertes convicciones, su compromiso social le llevó al mundo de la educación de la clase trabajadora (desde 1854 colabora en el Working's Men College donde entablaría amistad con William Morris). El activismo de Ruskin mantuvo una fuerte presencia en la sociedad inglesa hasta su muerte en 1900, convirtiéndose en una de las voces más críticas con la sociedad industrial y el capitalismo, entremezclando siempre en su discurso la exaltación de la arquitectura neogótica.

Esta idealizada mirada hacia un tiempo superado, tuvo su materialización en la obra de William Morris, un arquitecto que abandonó su disciplina para dedicarse a la construcción artesana de muebles en estrecha colaboración con los pintores prerrafaelitas y los arquitectos del movimiento inglés de la «arquitectura libre». Morris trabajó casi toda su vida recreando el mundo artesano de los talleres promulgando la máxima de la «obra de arte total» (tan apreciada pocos años después en Alemania por la Bauhaus o en Francia por Le Corbusier) dentro del movimiento Arts \& Crafts.

El éxito del taller de Morris le obligó a abrir unas dependencias en Londres en 1877 , donde sus artesanos diseñaban desde muebles hasta alfombras y vidrieras. Morris (una personalidad compleja no exenta de contradicciones) no dudó en tomar el testigo del anciano Ruskin en defensa de los ideales socialista y conservacionista, adoptando una postura cada vez más radical en sus planteamientos políticos, llegando a abandonar ia Federación Social Democrática encabezada por Engels para formar su propia Liga Socialista que dirigiera hasta su muerte en 1896.

Dentro de este clima surgió una arquitectura paralela al Arts \& Crafts que también deseaba reflejar esta idea de recuperación de un pasado más cercano al mundo rural que a la nueva ciudad industrial. En 1877 Richard Norman Shaw, seguidor también de los ideales de Ruskin, dirigió a un grupo de arquitectos en el diseño de la primera colonia jardín suburbana, Bedford Park, ideada para clases medias y altas, de enorme influencia en realizaciones como la ya mencionada Port Sunlight. Al año siguiente, Shaw publicó Sketches for Cottages and Other Buildings, obra ilustrada de gran influencia donde mostraba numerosos ejemplos de casas para trabajadores en distintos tamaños.

Aunque sin duda alguna, el hombre que mejor fijó y sistematizó teóricamente los principios de la ciudad jardín fue Ebenezer Howard, definiendo claramente un camino que la vivienda social recorrería a partir de ahora y hasta los años 30 , la colonia obrera suburbana. Como ha señalado Kenneth Frampton «la evolución del movimiento de la ciudad jardín en la última década del siglo estuvo estrechamente ligada al desarrollo del movimiento Arts \& Crafts. Tal como lo presentó E. Howard en 1898, la política social de la ciudad jardín combinaba la dispersión urbana con la colonización rural y el gobierno descentralizado. Como complemento del 
movimiento cooperativo, defendía que esa ciudad debería extraer sus rentas de una equilibrada combinación de industria y agricultura.»16

Los conocidos principios de la ciudad jardín de Howard, quien como Shaw también frecuentaba los círculos socialistas, quedaron expuestos en su famosa obra Tomorrow: a Peaceful Path to Real Reform (1892) reeditada en 1902 ya con el título Garden Cities of Tomorrow. El Garden Movement recogía buena parte de las teorías de Howard y se convertirá en una nueva y exitosa propuesta de teoría urbana. Sin embargo la primera comunidad basada en estos principios, Letchworth Garden City (iniciada en 1904 por Raymond Unwin y Barry Parker), trastocaba los ideales de Howard al entremezclar vías de transporte, zona residencial y fábricas al gusto de los diseñadores del proyecto.

Llegados a este punto, dentro del hervidero de compañías y asociaciones de artistas y artesanos que proliferaban en la Inglaterra de finales del XIX, siempre bajo el paraguas de los ideales de la reforma social, la arquitectura no parecía encontrar una salida clara. Por eso, una de las formulaciones más interesantes de este momento, y que se convertiría en el camino que seguirán los arquitectos alemanes, nos la ofrece C. R. Ashbee, influido por Morris y Ruskin, quien en 1887 discrepaba con ambos por su dogmática aversión a la máquina, autocalificándose como un socialista constructivo.

Unos años después, a principios de siglo y tras su encuentro con Frank Lloyd Wright, Ashbee se reafirmaba «en su creencia de que la resolución del dilema cultural planíeado por la industria moderna dependía del uso adecuado de la máquina." $Y$ al igual que Howard abogaba por la descentralización de las concentraciones urbanas existentes y de sus instituciones, dando con ello un apoyo adicional al vínculo entre el movimiento Arts \& Crafts y la idea de la ciudad jardín. " ${ }^{17}$ De esta forma, no nos puede extrañar, que el último de los «socialistas neogóticos», William Richard Lethaby, animara en 1915 a sus colegas británicos a buscar en Alemania y la Deutsche Werkbund el camino hacia el futuro. ${ }^{18}$

En definitiva, el socialismo utópico de Owen o Fourier había generado una corriente ideológica y un debate que continuaron y retomaron una buena parte de los artistas y arquitectos ingleses de la segunda mitad del siglo XIX. Principalmente los pertenecientes al Arts \& Crafts, continuadores de los principios expuestos por

16 Framptom, K.: Op. cit., pág. 47.

17 Ibídem, pág. 48. Sobre la relación entre arquitectura y el movimiento inglés, ver: DAvEY, Peter: L'architecture Arts \& Crafts. Bruxelles, Pierre Mardaga éd., 1987.

18 Pasando de ser uno de los fundadores en 1884 de la Arts Workers' Guild, asociación de trabajadores de arte que institucionalizaban los principios del movimiento Arts \& Crafts, a ser en 1915 uno de los promotores de la Design and Industries Association. WATKIN, David: Moral y Arquitectura, Barcelona, Tusquets, 1981, págs. 53-58. 
Pugin, Ruskin y Morris, quienes tras el fracaso de la utópica ciudad obrera (en sus múltiples formas de falansterios o familisterios) buscaron en la artesanía y en su compromiso socialista la huida, que no la salida, a los problemas generados por la irrefrenable industrialización. Dentro de este nuevo camino ideológico, marcado por la recuperación de un modo de vida que, si en el arte se reflejaba en la recuperación del mundo artesano, en la arquitectura se mostraría a través del retorno a una vida en un entorno próximo a lo rural, con las construcciones de las ciudades jardín. Las propuestas de la ciudad jardín tuvieron un éxito fulminante y se prodigaron por Europa un buen número de nuevas construcciones urbanas que seguían las formas expresadas por Howard.

Pronto se vio que el retorno a la artesanía y las construcciones semiurbanas no respondían a las soluciones reales de los problemas de la clase obrera, la mayor parte poco o nada cualificada para el trabajo artesano, o incapaz de alcanzar las rentas mínimas exigibles para adquirir una vivienda unifamiliar sin ningún tipo de ayuda. Las salidas que ofrecían la artesanía y la ciudad jardín eran definitivamente limitadas y más atrayentes para las clases medias que para el depauperado medio obrero.

El camino elegido al entrar en el siglo $\mathrm{xx}$ por artistas $\mathrm{y}$ arquitectos ingleses no parecía ofrecer una solución realista y alcanzable en las actuales situaciones socioeconómicas de la Europa occidental.

Si el problema era la industria, la solución podría encontrarse en ella misma, era lo que habían intuido ya Ashbee y Lethaby en Inglaterra pero que comprenderían y desarrollarían de forma concreta en la Alemania de las primeras décadas del siglo $\mathrm{xx}$, haciendo una lectura positiva de la experiencia británica, aunque adaptándola desde las posturas socialistas hacia un desarrollo más pragmático.

\section{UNA SALIDA: LA INDUSTRIA ALEMANA YLA «OBRA DE ARTE TOTAL»}

Esta lectura positiva contó con la inestimable ayuda de Hermann Muthesius, quien había residido en Londres como agregado de la embajada alemana desde 1896 hasta 1904 con el encargo de estudiar la arquitectura y el diseño ingleses, convirtiéndose a su regreso en el introductor en su país de las teorías de Ruskin y Morris, y de la concepción artesanal de las Arts \& Crafts. El mismo año de su regreso Friedrich Naumann había publicado un artículo llamado El arte en la era de la máquina, donde defendía que la calidad en la producción sólo podría ser alcanzada con un pueblo más cultivado en el arte y orientado hacia una mayor y mejor producción industrial, reflejando un sentir cada vez más generalizado en las 
clases políticas y económicas de Alemania, conscientes de que para competir en la nueva economía «mundial» la única salida radicaba en la mejora de la calidad.

Muthesius había recibido ese mismo año por parte del gobierno alemán el encargo de reformar el programa educativo en el terreno de las artes decorativas ${ }^{19}, y$ al igual que Naumann publicaba un texto exponiendo su modelo ideal de cultura artesanal, donde afirmaba que artesanía y, lo que es destacable en este momento, economía, eran los fundamentos del buen diseño y la clave del éxito de la arquitectura y el mobiliario Arts \& Crafts.

En 1906 se produjo un hecho clave en la evolución del movimiento artesano inglés Arts \& Crafts al contexto alemán que abogaría por un diseño industrial, cuando Muthesius, como comisario de la Tercera Exposición Alemana de Artes y Oficios celebrada en Dresde, se alineó con Naumann y Schmidt frente al grupo conservador y proteccionista, abogando clara y públicamente por la producción en serie.

En 1907 estos tres personajes fundaban la Deutsche Werkbund, junto con artistas y críticos como Behrens, Hoffmann, Olbrich, Bruno Taut o Schultze-Naumburg, contando con la importante adhesión de doce empresas artesanas. Aunque dentro de este heterogéneo conglomerado no todos coincidían con la apuesta de Muthesius a favor de un diseño normativo para la producción industrial ${ }^{20}$, como quedaría patente años más tarde.

La Deutsche Werkbund jugó un papel muy influyente sobre la política cultural de su país. Su idea consistía en obtener la conjunción perfecta entre arte e industria y propugnar una vivienda moderna, llevando a cabo las primeras tentativas europeas de tipificación de viviendas y de sistemas de producción en serie (aunque sólo en mobiliario) en las exposiciones de la Werkbund (Munich, 1908; ...).

En la línea inglesa, Muthesius planteaba la necesidad de construir barrios periféricos de baja densidad, sin los defectos de la urbanización compacta que se había ido realizando en Berlín en la segunda mitad del siglo XIX. La ciudad-jardín inglesa era uno de sus modelos más admirado, y lo consideraba capaz de adaptarse con éxito a los ensanches de las ciudades alemanas. El modelo de vivienda doméstica que había visto en Inglaterra le entusiasmaba por su funcionalidad y comodidad. Sus amplias investigaciones sobre la cultura del habitar inglesa, junto a su conocimiento de la ciudad-jardín, le llevaron a tipificar los usos edilicios ingleses y a estudiar sus principios de lógica y confort.

19 Este movimiento reformador de las artes y oficios habia tenido sus precedentes en la fundación por parte de Karl Schmidt de los «talleres de artesanía» de Dresde (1898), y en 1903 con el encargo de dirección de los talleres de artes y oficios de Dusseldorf a Peter Behrens. Frampton, K.: Op. cit., pág.112.

20 Un principio que tenía un precedente teórico en el arquitecto revolucionario alemán Gottfried Semper, huido a Londres, donde publicó en 1851 Ciencia, industria y arte, texto analizador del impacto de la industria y el consumo sobre las artes aplicadas y la arquitectura. 
Así mismo Muthesius, junto a Richard Riemerschmid y especialmente Heinrich Tessenow, fueron los autores de la ciudad-jardín alemana de Hellerau (19091917), obra que conjugaba calidad formal y que presentaba aspectos teóricos que estarían presentes en los años siguientes, especialmente en su lectura de reactualización de la tradición.

Es llamativo sin embargo, que Muthesius no llegara a trasladar plenamente sus principios sobre la tipificación y la producción en serie al terreno de la vivienda (acomodado aún en los principios de la ciudad jardín inglesa expresados arquitectónicamente a través de un clasicismo reinterpretado), principios formulados en un decálogo expuesto en el congreso de la Deutsche Werkbund celebrado en CoIonia en $1914^{21}$, y que se vio obligado a retirar ante el rechazo de sus compañeros liderados por Henry van de Velde con el apoyo de un nuevo miembro del grupo, Walter Gropius.

Walter Gropius, había trabajado junto a Adolf Meyer en el estudio de Peter Behrens (encargado desde 1907 de la arquitectura y diseño de la AEG) entre 1910 y 1914. En marzo de 1910 envió a Emil Rathenau (el fundador de la AEG en 1883) un memorando sobre la producción racionalizada de viviendas con el ejemplo de las casas para trabajadores que había proyectado para Janikow en 1906. «Este texto, escrito por Gropius a los veintiséis años, sigue siendo todavía hoy una de las exposiciones más completas y lúcidas que se han hecho nunca acerca de las condiciones previas esenciales para el éxito de la prefabricación, el montaje y la distribución de viviendas normalizadas». ${ }^{22}$

Gropius se convierte de este modo en el elemento catalizador de todo un proceso evolutivo iniciado en Inglaterra a mediados del siglo XIX, al heredar la preocupación de la arquitectura por la vivienda obrera, y al reinterpretar, gracias a Muthesius, el camino iniciado por el movimiento Arts \& Crafts, de aplicar el diseño a la fabricación de la vivienda social, pero desde las enormes posibilidades que ofrecía la tipificación industrial.

\section{EL CAMINO DE REGRESO A LA UTOPIA}

La fundación de la Bauhaus en 1919 por parte de Walter Gropius supuso el triunfo de la tendencia racionalizadora y modular frente a los críticos presentes en

${ }^{21}$ Muthesius explicaba en su decálogo: «En esencia, la arquitectura tiende hacia lo típico. El tipo descarta lo extraordinario y establece el orden», y este tipo, señala Frampton, tiene una vertiente de "objeto tectónico, un elemento constructivo irreductible que actuaba como unidad básica del leguaje arquitectónico". Frampton, K:: Op. cit., pág. 118.

22 Ibídem, pág. 116. 
el continuo debate de la Deutsche Werkbund antes de la primera gran guerra, y de la objetividad de la forma y el cientifismo utilitario. Gropius defendía un programa de "racionalización» desde la cadena de montaje hasta la planificación urbana, respetando al artista-artesano que había superado la división social del trabajo manual-intelectual. La Bauhaus basaba su organización en un sistema de integración de todas las artes que contó con el apoyo de artistas como Klee, Kandinsky o Moholy-Nagy y arquitectos como Richter o Mies van der Rohe. Esta escuela «representará un magnético centro de gravitación y de reelaboración de las ideas de vanguardia a escala internacional, que terminará por trascender el objetivo inicial de la integración de las artes para abordar directamente los temas de la proyección urbana». ${ }^{23}$

En 1925 Gropius publicó su ensayo Arquitectura Internacional ${ }^{24}$, base de sus posteriores investigaciones sobre tipologías edilicias ( $y$ los cimientos del urbanismo de los CIAM), paralelas a las de arquitectos como Alexander Klein o el propio Mies. Gropius desarrolló los Siedlung (como la residencia de profesores de la Bauhaus en Dessau, 1926-1928), proyectos que surgían del entorno rural (la continua influencia de Howard) desde donde una plaza central distribuía una red de pequeñas calles radiales flanqueadas por una cortina continua de casas bajas con huerto trasero individual. Estas casas eran unas viviendas en serie ampliables que favorecían la reducción del coste constructivo gracias al uso de los posibles sistemas de racionalización, montando sobre el terreno elementos prefabricados.

Uno de los mejores ejemplos realizados por Gropius lo constituía el Siedlung Dammerstock (Karlsruhe, 1927-1929; con la colaboración de Theodor Fischer y Otto Hesler), donde recurría a aspectos funcionales, tipológicos, industriales y teóricos que lo convirtieron en uno de los mejores siedlung alemanes. Otros arquitectos afines a trasladar la cadena de montaje al proceso constructivo fueron Martin Wagner y su proyecto del «Nuevo Berlín» (1924-1931), o el arquitecto municipal de Frankfurt (1925-1931) Ernst May. Quien consigue el mayor grado de industrialización en la construcción de viviendas en la Alemania de entreguerras, levantando 15.000 viviendas de un racionalismo atemperado, como resultado de su aprecio a la tradición (y su formación con Unwin), en un modelo sin precedentes de planificación coordinada que respeta el sentido del paisaje y la naturaleza del Siedlung.

En definitiva, la necesaria reconstrucción europea tras la I Guerra Mundial posibilitó un camino, aunque dramático, para la construcción de la vivienda indus-

23 Gravagnuolo, B.: Historia del urbanismo en Europa, 1750-1960. Madrid, Akal, 1998, págs. 366-367.

24 El mismo año de la fundación del grupo Der Ring para la difusión de la nueva arquitectura, integrado por el propio Gropius junto a arquitectos de diferentes tendencias como Mies, Taut, Mendelsonn o Hilberseimer. 
trializada y racionalizada favorecedora de la tipificación a través de los incipientes procesos de modulación en serie.

La arquitectura y la vivienda social en los años 20 convergen por primera y últíma vez en un único camino. Estudiar la arquitectura y el urbanismo del periodo de entreguerras supone conocer las nuevas teorías urbanas y constructivas de Le Corbusier, de los arquitectos holandeses, soviéticos, alemanes o austriacos, sobre vivienda social. La nueva arquitectura, el racionalismo y el funcionalismo expresado en la masiva creación de barrios residenciales, estaban a punto de ahogar definitivamente el eclecticismo-historicismo-academicismo heredado del siglo XIX. ${ }^{25}$

El proyecto práctico de maduración teórica más importante, el éxito de esta relación entre vivienda social y arquitectura, hasta la corriente homogeneizadora de los congresos CIAM, tuvo lugar con la exposición de la Werkbund en Stuttgart en 1927, la Weissenhorsiedlung dirigida por Mies van der Rohe, un completo «barrio de exposición» concebido como manifiesto internacional de los nuevos prototipos habitacionales.

La vivienda en serie y la prefabricación están presentes en todos los grandes textos de la arquitectura de los años veinte, desde Le Corbusier hasta Fuller, desde Meyer a Ginzburg, desde Oud a Stam. El proceso experimental que vive la vivienda social en estos años, es de tal magnitud que se configura un diseño habitacional que es el precursor del actual. Nuestras viviendas de hoy día son herederas de estas viviendas sociales de los años 20 , el diseño y la configuración actual están basados en los principios enunciados y construidos por la arquitectura de vanguardia, nuestras cocinas y aseos son los herederos de los "experimentos" que transformaron la cocina y el aseo en un auténtico «laboratorio» en estas construcciones. Los principios de soleamiento, ventilación y orientación, irrenunciables en la vanguardia arquitectónica, avanzan los principios medioambientales y ecológicos de la vanguardia actual en busca de un desarrollo sostenible también en el campo de la vivienda.

Al final, una generación de arquitectos supo leer en la historia y encontró que la industria podría aportar los elementos necesarios. Siempre sin olvidar el hecho de que desde la Gran Exposición londinense de 1851 hasta la Weissenhofsiedlung alemana de 1927, en todas las grandes exposiciones universales hubo un hueco para la vivienda social, y no por casualidad, en el capítulo de avances técnicos.

El posicionamiento político de la arquitectura es otro elemento indiscutible. Las posturas políticas socialistas tomadas desde la arquitectura son un hecho relevante

25 Uno de los análisis más detallados e interesantes de la modificación de la vivienda en la pujante ciudad moderna de entreguerras en: MARTí ARIS, Carlos (ed.): Las formas de la residencia en la ciudad moderna. Barcelona, Servicio de Publicaciones de la UPC, 1991, págs. 13-48. 
no del todo estudiado y valorado. Pero que nos permite percibir un fino hilo entre utópicos, el movimiento Arts \& Crafts y el salto a Alemania, pasando de valorar el trabajo del artesano a buscar soluciones en defensa del obrero no alienado.

Antes de finalizar la década de 1920, el proceso estaba ya en su punto más maduro. El II CIAM (Frankfurt, 1929), bajo el lema de la "Vivienda Mínima», se dedicó al "análisis científico» de las tipologías habitacionales, los niveles mínimos de la vivienda y la altitud y el espaciado de las edificaciones, interesados por un uso más racional del terreno y la superficie. ${ }^{26}$

Al año siguiente se celebraba el III CIAM en Bruselas con el eslogan «Métodos constructivos racionales", con la aportación de W.Gropius en su conocido informe Los presupuestos sociológicos de la vivienda mínima, un análisis de la vivienda que ejerció una enorme influencia en los años 30 y en la reconstrucción tras la Guerra Mundial. En 1933, en el IV CIAM con el tema de "La ciudad funcional», se firmó la «Carta de Atenas», basada en las posiciones de Le Corbusier —animador de los CIAM-, fin teórico de los principios de la ciudad histórica. A partir de aquí el urbanismo fue el eje central de los congresos, y el funcionalismo se erigió en el método de proyección urbana, decantándose por la edificación en altura como solución frente al caos residencial, en medio de una rígida zonificación, abandonando definitivamente el pintoresquismo y el ruralismo de la ciudad jardín, incapaz de solucionar en la realidad el problema del alojamiento en la ciudad capitalista contemporánea.

Hacia una nueva arquitectura, la obra publicada por Le Corbusier en 1923, dedicaba un capítulo a las maisons en serie, junto a otro dedicado a la revolución social fomentada por la nueva arquitectura basada en la industria, insistiendo una vez más en la crítica a lo mal alojadas que se encontraban las clases trabajadoras. La escala de una solución que Le Corbusier sí se atrevió a expresar, debía combinar la nueva arquitectura basada en la industrialización y la prefabricación con un nuevo diseño urbano de tal magnitud que dieran como fruto la nueva ciudad contemporánea: la Ville Contemporaine presentada por le Corbusier en 1922, a base de sus bloques de células que tenían su origen en los Aeródromos parisinos de Henry Jules Borie (1865) y el hierro y cristal tomado del módulo de Paxton en su Crystal Palace. ${ }^{27}$ Una solución basada en experiencias construibles pero que no dejaba de ser utopía, la diferencia con Owen radicaba en la paradoja que supone cambiar de escala la propia utopía. Mientras el inglés soñaba con alojar en condi-

$26 \mathrm{Y}$ en este momento Inglaterra ya se sumaba a las corrientes europeas con las primeras construcciones de viviendas sociales influenciadas por Le Corbusier y la Bauhaus a modo de «cubos blancos». Colquhoun, lan: RIBA Book of 20th Century British Housing, Oxford, Butterworth-Heinemann, 1999, pág.7.

27 Frampton, K.: Le Corbusier, Londres, Thomas \& Hudson, 2001, pág. 48. 
ciones dignas a la clase obrera en pequeñas ciudades, Le Corbusier, punta de lanza del urbanismo de vanguardia, soñaba con alojar dignamente a toda la ciudad, a toda la humanidad, y proyectó su nueva visión utópica para cambiar por completo ciudades como París o Barcelona, e incluso para saltar de Europa y cambiar por completo ciudades como Argel o como Río de Janeiro. 
$\ldots$ 